\title{
Teaching Critical Thinking and Problem-Solving Skills to Healthcare Professionals
}

\author{
Jessica A. Chacon ${ }^{1} \cdot$ Herb Janssen ${ }^{1}$ (D) \\ Accepted: 15 October 2020 / Published online: 27 October 2020 \\ (C) International Association of Medical Science Educators 2020
}

\section{Introduction}

Determining approaches that improve student learning is far more beneficial than determining what can improve a professor's teaching. As previously stated, "Lecturing is that mysterious process by which the contents of the note-book of the professor are transferred through the instrumentation of the fountain-pen to the note-book of the student without passing through the mind of either" [1]. This process continues today, except that the professor's note-book has been replaced with a PowerPoint lecture and the student's note-book is now a computer.

In 1910, the Flexner report noted that didactic lectures were antiquated and should be left to a time when "professors knew and students learned" [2]. Approximately 100 years later, the Liaison Committee on Medical Education (LCME) affirmed Flexner's comment and suggested that student learning must involve active components [3]: It seems somewhat obscured that almost 100 years separated these two statements.

Our strategy requires the following: student engagement in the learning process; a curriculum that develops a foundation for each student's knowledge acquisition; focusing primarily on student learning instead of professor teaching; helping enable students develop critical thinking skills; and encouraging students to develop "expertise" in their chosen discipline.

Six fundamental topics that play a role in the development of a health sciences student's critical thinking ability will be described. In "Section I," these topics will be discussed independently, highlighting the importance of each. In "Section II: Proposed Curriculum and Pedagogy to Improve Student Learning," the topics will be united into a practical approach that can be used to improve student learning, curriculum, pedagogy, and assessment.

Herb Janssen

herb.janssen@ttuhsc.edu

1 Department of Medical Education, Paul L Foster School of Medicine, Texas Tech University Health Sciences Center El Paso, El Paso, TX, USA

\section{Section I}

\section{Foundation Knowledge}

Students use mnemonics to provide a foundation for new information. Although mnemonics help students associate information that they want to remember with something they already know, students learn tads of information that is not placed into a practical, meaningful framework developed by the student $[4,5]$. This commentary highlights the problem of recalling facts when these facts are presented in isolation. The responsibility for this resides not with the student, but with a curriculum that teaches isolated facts, instead of integrated concepts.

A taxonomy for significant learning presented by Dr. Fink emphasizes the need to develop foundational knowledge before additional information can be learned in an effective manner [6]. He provides suggestions on developing specific learning goals in given courses. Two of his most important criteria are (1) the development of a foundation of knowledge and (2) helping students "learn how to learn" [6].

\section{Learning Approaches and Abilities}

Howard Gardner introduced the concept of multiple intelligences in the 1980s [7]. Gardner expanded this idea to include intelligence in the areas of (1) Verbal-linguistic, (2) Logicalmathematical, (3) Spatial-visual, (4) Bodily-kinesthetic, (5) Musical, (6) Interpersonal, (7) Intrapersonal personal, (8) Naturalist, and (9) Existential. He concluded that students gifted in certain areas will be drawn in that direction due to the ease with which they excel. While it is important to recognize these differences, it is crucial to not ignore the need for student development in areas where they are less gifted. For example, students gifted in mathematics who fail to develop intrapersonal and interpersonal skills will more likely become recluse, limiting their success in real-world situations $[7,8]$. Similar examples can also be found in the medical world $[7,8]$. 
Based on Gardner's work, it seems evident that students admitted to our health sciences schools will arrive with different skills and abilities. Despite this, educators are required to produce graduates who have mastered the competencies required by the various accrediting agencies. Accomplishing this task demands sensitivity to the students' different abilities. While the curriculum remains focused on the competencies students must demonstrate when training is complete. Creating this transition using a traditional lecture format is difficult, if not impossible.

\section{Active Engagement}

In 1910, Flexner suggested that didactic lecture is important; however, it should be limited only to the introduction or conclusion of a given topic [2]. Flexner stated that students should be given the opportunity to experience learning in a context that allowed them to use scientific principles rather than empirical observations [2]. Active engagement of the student in their learning process has been recently promoted by the LCME [3]. This reaffirmation of Flexner's 1910 report highlights the incredibly slow pace at which education changes.

\section{Critical Thinking}

Critical thinking is an active process that, when applied appropriately, allows each of us to evaluate our own activities and achievements. Critical thinking also allows an individual to make minor, mid-course corrections in thinking, instead of waiting until disastrous outcomes are unavoidable.

Educators in Allied Health and Nursing have included critical thinking as part of their curriculum for many years [9]. Medical educators, on the other hand, have not fully integrated critical thinking as part of their curriculum [10, $11]$.

Bloom's taxonomy has often been used to define curriculum [12]. The usefulness and importance of Bloom's taxonomy is not to be underestimated; however, its limitations must also be addressed. As Bloom and his colleagues clearly stated, their taxonomy describes behavioral outcomes and is incapable of determining the logical steps through which this behavior was developed [12]. Bloom highlights this shortcoming in his initial book on the cognitive domain. He described two students who solved the same algebra problem. One student does this by rote memory, having been exposed to the problem previously, while the other student accomplishes the task by applying mathematical principles. The observer has no way of knowing which approach was used unless they have prior knowledge of the students' background [12]. The importance of this distinction becomes apparent in medical problem-solving.

\section{Contextual Learning}

Enabling students to learn in context is critical; however, trying to teach everything in context results in a double-edged sword [13]. On the one hand, learning material in context helps the student develop a solid foundation in which the new information can be built. On the other hand, the educator will find it impossible to duplicate all situations the student will encounter throughout his or her career as a healthcare provider. This dilemma again challenges the educator to develop a variety of learning situations that simulate real-world situations. It seems that "in context" can at best be developed by presenting a variety of patients in a variety of different situations.

In the clinical setting, the physician cannot use a strict hypothesis-driven study on each patient, but must treat patients using the best, most logical treatment selected based on his or her knowledge and the most reliable information.

\section{Development of Expertise}

Several researchers have studied the characteristics required of expert performance, the time required to obtain these traits, and the steps that are followed as an individual's performance progresses from novice to expert.

Studies involving expert physicians have provided data that can be directly used in our attempt to improve curriculum and pedagogy in the healthcare profession. Patel demonstrated that medical students and entry-level residents can recall a considerable amount of non-relevant data while the expert cannot [14]. Conversely, the expert physician has a much higher level of relevant recall, suggesting they have omitted the non-relevant information and retained only relevant information that is useful in their practice. Using these methods, the expert physicians produce accurate diagnosis in almost 100\% of cases, while the medical students can achieve only patricianly correct or component diagnosis only [14].

In the healthcare setting, both methods are used. The expert physicians will use forward reasoning when the accuracy of the data allows this rapid problem-solving method. When the patient's conditions cannot be accurately described using known information, the expert diagnostician will resort to the slower hypothesis-driven, backward reasoning approach. In this manner, the highest probability of achieving an accurate diagnosis in the shortest time will be realized [14].

\section{Section II: Proposed Curriculum and Pedagogy to Improve Student Learning}

The following section will outline several distinct but interrelated approaches to accomplish the six educational principles discussed above. The topics will be highlighted as they apply 
to the specific topic and each section will be comprised of curriculum, pedagogy, and assessment.

\section{Developing a Knowledge Base Using Active Learning Sensitive to Students' Abilities}

Students admitted into healthcare training programs come from various backgrounds. This is both a strength for the program and a challenge for the educator. The strength is recognized in the diversity the varied backgrounds bring to the class and ultimately the profession. The challenge for the educator is attempting to provide each student with the material and a learning approach that will fit their individual ability and knowledge level. The educator can provide prerequisite objectives that identify the basic knowledge required before the student attempts the more advanced curriculum. Scaffolding questions can also be provided that allow students to determine their mastery of these prerequisite objectives. Briefly, scaffolding questions are categorized based on complexity. Simple, factual questions are identified with a subscript "0" (i.e. 1.0, 2.0, etc.). Advanced questions have a subscript suggesting the estimated number of basic concepts that must be included/combined to derive the answer.

Using technology to provide these individual learning opportunities online allows each student to address his or her own potential deficits. Obviously, those who find their knowledge lacking will need to spend additional time learning this information; however, using technology, this can be accomplished without requiring additional class time. This approach will decrease learning gaps for students, while excluding unnecessarily repeating material known by others.

Curriculum The curriculum is divided into two parts: (1) content and (2) critical thinking/problem-solving skills. The basic knowledge and factual content can be provided online. Students are expected to learn this by actively engaging the material during independent study. This saves classroom or small-group sessions for interaction where students can actively learn critical thinking/problem-solving skills.

The curriculum should be designed so that students can start at their own level of understanding. The more advanced students can identify the level appropriate for themselves and/ or review the more rudimentary information as needed. As shown by previous investigators, experts omit non-relevant information so that they can focus on appropriate problemsolving. Requiring students to learn by solving problems or exploring case studies will be emphasized when possible.

Pedagogy Technology can be used to deliver the "content" portion of the curriculum. Voice-over PowerPoints and/or video clips made available online through WebCT or PodCast will allow each student to study separately or in groups at their own rate, starting at their own level of knowledge. The content delivered in this fashion will complement the handout and/or textbook information recommended to the students. This will provide the needed basic information that will be used as a foundation for the development of critical thinking and problem-solving. The flipped classroom and/or team-based learning can both be used to help facilitate this type of learning. [15]

Student Assessments It is imperative for students to know whether they have mastered the material to the extent needed. This can be accomplished by providing online formative evaluations. These will not be used to determine student performance; however, the results will be provided to the educator to determine the class's progress and evaluation of the curriculum.

\section{Developing Critical Thinking Skills in the Classroom or Small-Group Setting}

Critical thinking skills are essential to the development of well-trained healthcare professionals. These skills are not "taught" but must be "learned" by the student. The educator provides learning experiences through which the students can gain the needed skills and experience. Mastery of the content should be a responsibility placed on the student. Information and assistance are given to the students, but students are held accountable for learning the content. This does not indicate that the educator is freed from responsibility. In fact, the educator will most likely spend more time planning and preparing, compared to when didactic lectures were given; however, the spotlight will be placed on the student. Once the learning modules are developed, they can be readily updated, allowing the educators to improve their sessions with each evaluation.

Curriculum Curriculum designed to help student students develop critical thinking/problem-solving skills should be learned in context. During the introductory portions of the training, this can be accomplished by providing problembased scenarios similar to what will be expected in the later clinical setting. The transition to competency-based evaluation in many disciplines has made this a virtual necessity. Critical thinking/problem-solving skills should emphasize self-examination. It should teach an individual to accomplish this using a series of steps that progress in a logical fashion, stressing that critical thinking is a progression of logical thought, not an unguided process.

Pedagogy The methods of teaching critical thinking can be traced back to the dialectic methods used by Socrates. Helping the students learn by posing questions remains an effective tool. Accomplishing this in a group setting also provides each student with the opportunity to learn, not only from their mistakes and accomplishments, but from the mistakes and 
accomplishments of others. Scenario questions can be presented in a manner similar to those found in many board and licensure exams. This exposes students to material in a format relevant to the clinical setting and to future exams. In larger groups, PowerPoint presentation of scenario questions can be used. Team-based learning (TBL) is useful in encouraging individual self-assessment and peer-peer instruction, while also providing an opportunity for the development of critical thinking and problem-solving skills. After the Individual Readiness Assurance Test (iRAT) exam, students work together to answer the Group Readiness Assurance Test (gRAT). Following this, relevant material is covered by clinicians and basic scientists working together and questions asked using an audience response system. This has been useful in encouraging individual self-assessment and peer-peer instruction while also providing an opportunity for the development of critical thinking and problem-solving skills.

Assessment Formative assessment of the students will be given in the class session. This can be accomplished using an audience response system. This gives each individual a chance to determine their own critical thinking skill level. It will prevent the "Oh, I knew that" response from students who are in denial of their own inabilities. Summative assessment in the class will be based on the critical thinking skills presented in the classroom or small-group setting. As mentioned earlier, the students will be evaluated on their ability to think critically and to problem-solve. This will by necessity include evaluation of content knowledge - but only as it pertains to the critical thinking and problem-solving skills. This will be made clear through the use of objectives that describe both content and critical thinking.

\section{Enhancing Critical Thinking Skills in Simulation Centers and Clinics}

The development of critical thinking skills in healthcare is somewhat unique. In chess, students can start playing using the same tools employed by the experts (the chess board); however, in healthcare, allowing students to make medical decisions is ethically inappropriate and irresponsible. Simulations centers allow students to gain needed experience and confidence without placing patients at risk. Once the students have mastered simulation center experiences and acquired the needed confidence, they can participate in patient diagnosis under the watchful eye of the expert healthcare professional.

Curriculum The student's curriculum now becomes the entire knowledge base of each healthcare discipline. This includes textbooks and journal articles. Students are required to come well prepared to the clinics and/or hospital having developed and in-depth understanding of each patient in their care.

Pedagogy Each day, the expert healthcare provider, serving as a mentor, will provide formative evaluation of the student and his/her performance. Mentors will guide the student, suggesting changes in the skills needed to evaluate the patients properly. In addition, standardized patients provide an excellent method of student/resident evaluation.

Assessment Summative evaluation is in the form of subject/board exams. These test the student's or resident's ability to accurately describe and evaluate the patient. The objective structured clinical examination (OSCE) is used to evaluate the student's ability to correctly assess the patient's condition. Thinking aloud had been previously shown as an effective tool for evaluating expert performance in such settings [16]. Briefly, think aloud strategies require the student to explain verbally the logic they are using to combine facts to arrive at correct answers. This approach helps the evaluator to determine both the accuracy of the answer and if the correct thought process was followed by the student.

\section{Summary}

If the time required to develop an expert is a minimum of ten years, what influence can education have on the process?

Education can:

1. Provide the student with a foundation of knowledge required for the development of future knowledge and skills.

2. Introduce the student to critical thinking and problemsolving techniques.

3. Require the student to actively engage the material instead of attempting to learn using rote memory only.

4. Assess the performance of the student in a formative manner, allowing the lack of information of skills to be identified early, thus reducing the risk of failure when changes in study skills are more difficult and/or occur too late to help.

5. Provide learning in a contextual format that makes the information meaningful and easier to remember.

6. Provide training in forward reasoning and backward reasoning skills. It can relate these skills to the problemsolving techniques in healthcare.

7. Help students develop the qualities of an expert healthcare provider. 
Authors' Contributions The authors wrote and contributed to the final manuscript.

Data Availability NA

\section{Compliance with Ethical Standards}

Conflict of Interest The authors declare that they have no conflict of interest.

Ethics Approval N/A

Code Availability NA

\section{References}

1. Maguire ER. The group-study plan: a teaching technique based on pupil participation: Sharles Charles Scribner's Sons; 1928.

2. Flexner A. Medical education in the United States and Canada. From the Carnegie Foundation for the Advancement of Teaching, bulletin number four, 1910. Bull World Health Organ 2002;80(7): 594-602.

3. Liaison Committee on Medical Education [Available from: https:// lcme.org/.

4. Learning WC. Chapter 6: Kinds of mnemonics [Available from: $\mathrm{http}: / /$ college.cengage.com/collegesurvival/wong/essential_study/ 6e/assets/students/protected/wong_ch06_in-depthmnemonics. $\mathrm{html}$.

5. Wong L. Essential study skills. Boston: Wadsworth, Inc.; 2015.
6. Fink LD. Creating significant learning experiences. San Francisco: Jossey-Bass; 2003.

7. Gardner H. Frames of mind: the theory of multiple intelligences. New York: Basic Books; 1983.

8. Gardner H. Multiple intelligences: the theory in practice. New York: Basic Books; 1993.

9. Alfaro-LeFevre R. Critical thinking in nursing: a practical approach. 2, illustrated ed: Saunders, 1999.

10. Sharple JM, Oxman AD, Mahtani KR, Chambers I, Oliver S, Colins K, et al. Critical thinking in healthcare and education. BMJ. 2017;357:2234.

11. Kahlke R, Kevin E. Constructing critical thinking in health professional education. Perspect Med Educ. 2018;7(3):156-65.

12. Bloom BS, MD E, Furst E, Hill W, Krathwohl DR. Taxonomy of educational objectives. Handbook I: cognitive domain. New York: David McKay Co Inc.; 1956.

13. Laurillard D. Rethinking university teaching. New York: London: Routledge Falmer; 2002.

14. Patel V, Groen G. The general and specific nature of medical expertise: a critical look. In: Ericsson KA, Smith J, editors. Toward a general theory of expertise. New York: Cambridge. University Press; 1991.

15. Khe Foon HEW, Chung KLO. Flipped classroom improve students learning in health professions education: a meta-analysis. BMC Medical Education. 2018;18:38.

16. Brown JL, Ilgen JS. Now you see it, now you don't: what thinking aloud tells us about clinical reasoning. J Grad Med Educ. 2014;6(4): $783-5$.

Publisher's Note Springer Nature remains neutral with regard to jurisdictional claims in published maps and institutional affiliations. 